\title{
PENDIDIKAN KESEHATAN MEMPENGARUHI PERSEPSI REMAJA DALAM MERAWAT ORGAN REPRODUKSI
}

\author{
$\operatorname{Arfiah}^{凶}$ \\ Program Studi DIII Kebidanan Sekolah Tinggi Ilmu Kesehatan Widya Nusantara Palu
}

\section{ARTICLE INFO \\ Article history \\ Submitted : 2021-01-05 \\ Revised : 2021-01-07 \\ Accepted : 2021-01-14}

Keywords:
Health education
Perception
Teenagers
Reproductive organ

Kata Kunci:
Pendidikan kesehatan
Persepsi
Remaja
Organ reproduksi

Organ reproduksi

\begin{abstract}
Care of the reproductive organs is an initial effort to maintain reproductive health. Performing treatment of the wrong reproductive organs can cause infectious diseases in the reproductive organs. Based on the results of interviews the researcher obtained from 10 students that the behavior in caring for reproductive organs is not too well known. The research aims to find out the effect of health education on reproductive organ at Grade VIII of SMPN 7 Palu.This was a quantitative research with pre experimental design using one group pretest posttest deign. The research population was 41 respondents selected using total sampling. The data were analyzed through Wicoxon test. The data analysis used univariate analysis which is for analyzing a distribution of frequency is Of the 41 respondents who had perceptions about caring for reproductive organs before health education was carried out, 7 respondents $(17.1 \%)$ were in good category, 25 respondents $(61.0 \%)$ were in sufficient category, and 9 respondents $(22.0 \%)$ were in poor category. Of the 41 respondents who have perceptions about caring for reproductive organs after health education is carried out, 33 respondents $(80.5 \%)$ are in the good category, and 8 respondents (19.5) are in the moderate category, percentage of each viable while bivariate analysis used inferentially to search for the health education effect on reproductive organ at Grade VIII of SMPN 7 Palu, where the result of $p=0.00<\alpha=0.05$. In conclusion, there is a significant effect of Health Education on Teenagers' Perception in Caring Reproductive Organ at Grade VIII of SMPN 7 Palu. The suggestion is after conducting health education dealing with reproductive organ it is expected that they can form a well self-concept followed by a good behavior and for the health officers that they can provide education for the students in order that they can care it better.

Perawatan organ reproduksi merupakan usaha awal menjaga kesehatan reproduksi. Melakukan perawatan organ reproduksi yang keliru dapat menyebabkan terjadinya penyakit infeksi pada organ reproduksi. Berdasarkan hasil wawancara yang peneliti peroleh dari 10 siswa bahwa perilaku dalam merawat organ reproduksi belum terlalu mereka ketahui. Tujuan penelitian ini untuk mengetahui pengaruh pendidikan kesehatan terhadap persepsi remaja dalam merawat organ reproduksi pada kelas VIII di SMPN 7 Palu. Jenis penelitian ini kuantitatif, rancangan penelitian pre experiment dengan menggunakan desain one group pre test-post test design. Populasi dalam penelitian ini sebanyak 41 responden dengan tehnik pengambilan sampel total sampling. Analisis data menggunakan Uji Wicoxon. Analisis data menggunakan analisis univariat merupakan analisis untuk menghasilkan suatu distribusi frekuensi yaitu dari 41 responden yang memiliki persepsi tentang merawat organ reproduksi sebelum dilakukan pendidikan kesehatan pada kategori baik 7 responden $(17,1 \%)$, kategori cukup sebanyak 25 responden $(61,0 \%)$, dan kategori kurang 9 responden $(22,0 \%)$ dan dari 41 responden yang memiliki persepsi tentang merawat organ reproduksi sesudah dilakukan pendidikan kesehatan pada kategori baik 33 responden $(80,5 \%)$, dan kategori cukup sebanyak 8 responden $(19,5)$, presentase dari masing-masing variabel dan analisis bivariat yaitu secara inferensial untuk mencari pengaruh pendidikan kesehatan terhadap persepsi remaja dalam merawat organ reproduksi pada kelas VIII di SMPN 7 Palu, dimana hasil $\mathrm{p}=0,00<\alpha=0,05$. Simpulan dari penelitian ini bahwa ada pengaruh yang bermakna antara pengaruh pendidikan kesehatan reproduksi terhadap persepsi remaja dalam merawat organ reproduksi pada kelas VIII di SMPN 7 Palu. Saran setelah dilakukan pendidikan kesehatan mengenai perawatan organ reproduski diharapkan dapat membentuk konsep diri yang baik diikuti perubahan perilaku yang baik dan kepada tenaga kesehatan untuk memberikan edukasi kepada siswi agar dapat merawat organ reproduksi dengan baik.
\end{abstract}




\section{Corresponding Author:}

Arfiah

Program Studi DIII Kebidanan Sekolah Tinggi Ilmu Kesehatan Widya Nusantara Palu

Telp. 085242959545

Email: arfiah@stikeswnpalu.ac.id

\section{PENDAHULUAN}

Kesehatan reproduksi menurut World Health Organization (WHO) sehat mental dan sosial, yang bukan hanya bebas dari penyakit atau kecacatan dalam segala aspek yang berhubungan dengan sistem reproduksi, fungsi serta prosesnya dan berbagai macam permasalahan kesehatan lainnya. Permasalahan kesehatan reproduksi remaja termasuk pada saat pertama anak perempuan haid yang beresiko timbulya anemia, perilaku seksual yang mana bila kurang pengetahuan dapat tertular penyakit hubungan seksual (World Health Organization, 2014).

Menurut Badan Kependudukan dan Keluarga Berencana Nasional (BKKBN) remaja mengalami pertumbuhan dan perkembangan pesat pada aspek fisik, psikologis dan juga intelektual. Beberapa karakteristik remaja yaitu memiliki keingintahuan yang besar, menyukai petualangan dan tantangan serta berani menanggung risiko atas perbuatannya tanpa didahului oleh pertimbangan yang matang hal ini menimbulkan banyak permasalahan pada remaja, salah satunya adalah permasalahan mengenai kesehatan reproduksi $\underline{(B K K B N}$, 2013).

Remaja merupakan masa peralihan dari masa anak ke masa dewasa. Masa remaja ini terdiri dari tiga sub fase yaitu masa remaja awal (usia 12 - 16 tahun), masa remaja pertengahan (usia 17 - 19 tahun) dan masa remaja akhir (usia 19 - 24 tahun). Masa ini sering disebut dengan masa pubertas (Johar, Wiwin., Rejeki, Sri., Khayati, 2013).

Masa pubertas adalah periode tumbuh kembang fisik maupun mental manusia dari seorang anak menjadi dewasa. Tanda pubertas eksternal dilihat dari putting payudara yang berkembang dan areola yang membesar, tumbuhnya rambut aksila dan pubis, panggul melebar dan berkembang dengan cepat. Uterus dan ovarium juga berkembang dengan matang. (Prayitno, 2014).

Di saat masa pubertas pada remaja wanita harus menjaga dan merawat organ reproduksinya dengan baik karena apabila tidak terawat dengan baik maka akan menimbulkan kelainan atau gejala seperti keputihan (Prayitno, 2014).

Gejala keputihan muncul dikarenakan faktor hormonal, kebersihan atau perilaku hygiene yang kurang baik dan suasana $\mathrm{pH}$ vagina juga ikut memengaruhi gejala keputihan tersebut. Perilaku hygiene yang tidak baik dapat juga menimbulkan bau yang tidak sedap, dan munculnya penyakit seperti kanker serviks (K. Indrawati, 2011).

Berdasarkan data dari badan kesehatan dunia (WHO), kanker seviks merupakan kanker nomor dua terbanyak pada wanita berusia 15 45 tahun. Salah satu faktor penyebab kanker serviks yaitu kurangnya personal hygiene pada organ reproduksi. Berdasarakan World Cancer Research Fund International jumlah penderita kanker serviks di tahun 2012 adalah 528.000 dialami perempuan diseluruh dunia dan di Indonesia terdapat 15.027 kasus. Tahun 2013 penderita kanker serviks berjumlah 98.692 kasus (Kementerian Kesehatan Republik Indonesia, 2013).

Hal tersebut juga dibuktikan dari hasil penelitian (T. Indrawati \& Pitriyani, 2016) yang dilakukan di RSUP oleh Dr. Kariadi yang menyebutkan bahwa sebanyak 87,10\% memiliki personal hygiene yang kurang baik dan adanya kejadian kanker serviks stadium 3 yaitu sebanyak 58,1\%. Penelitian tersebut menyimpulkan adanya hubungan yang signifikan antara kanker serviks dengan personal hygiene organ reproduksi yang kurang baik. Dari hasil pembahasan tersebut maka remaja putri harus diberikan tambahan pengetahuan melalui pendidikan kesehatan tentang merawat organ reproduksi agar mereka dapat merawat dan memelihara organ reproduksinya dengan baik.

Adapun penelitian yang dilakukan oleh (Yusly et al., 2015) tentang pengaruh pendidikan kesehatan terhadap persepsi remaja dalam merawat organ genetalia pada remaja putri di SMAN 1 Pakusari Kabupaten Jember, hasil analisis data menunjukkan bahwa nilai rata-rata responden sebelum diberikan pendidikan kesehatan 71.46 dan setelah diberikan pendidikan kesehatan 83.95. Hasil uji 
statistic menggunakan paried $\mathrm{T}$-Tes dengan $=0,05$ didapatkan nilai $\mathrm{p}$ value 0,0009 .

Berdasarkan hasil wawancara dengan kepala sekolah SMPN 7 palu siswi putri di kelas VIII jumlah keseluruhan yaitu 41 orang, dan dilakukan wawancara pada tanggal 19 Juli 2020 di SMPN 7 Palu. Hasil wawancara dengan 10 siswa bahwa perilaku dalam merawat organ reproduksi belum terlalu mereka ketahui seperti mencebok hanya sekedarnya saja yang penting mereka anggap sudah bersih, padahal dalam mencebok itu dimulai dari daerah vagina lalu ke anus atau dari depan ke belakang. Oleh karena itu penting untuk dilakukannya pendidikan kesehatan, untuk mengetahui persepsi mereka sehingga akan mengetahui sejauh mana cara pandang remaja putri sesuai dengan ketentuan atau informasi yang diberikan. Tujuan dari penelitian ini adalah menganalisis pengaruh pendidikan kesehatan terhadap persepsi remaja dalam merawat organ reproduksi di SMPN 7 Palu.

\section{METODE PENELITIAN \\ Jenis Penelitian}

Jenis penelitian yang digunakan dalam penelitian ini adalah kuantitatif. Rancangan penelitian yang digunakan dalam penelitian ini adalah rancangan penelitian pre experiment dengan menggunakan desain one group pre test-post test design.

\section{Lokasi dan Waktu Penelitian}

Penelitian ini dilaksanakan di SMPN 7 Palu pada Bulan Juli Tahun 2020.

\section{Populasi dan Sampel}

Populasi dalam penelitian ini adalah semua siswi putri kelas VIII SMPN 7 Palu berjumlah 41 orang dengan umur $13-14$ tahun. Pengambilan sampel pada penelitian ini menggunakan cara Total Sampling.

\section{Pengumpulan Data}

Metode pengumpulan data yaitu dengan menggunakan data primer dan data sekunder. Dimana data primer didapatkan melalui pembagian kuesioner kepada siswa kelas VIII, data sekunder didapatkan melalui data sekunder yaitu data siswi di SMPN 7 Palu.

\section{Pengolahan dan Penyajian Data}

Pengolahan dan penyajian data dilakukan dengan menggunakan komputer program SPSS.
Data disajikan dalam bentuk tabel distribusi frekuensi yang disertai narasi atau penjelasan.

\section{Analisis Data}

Analisis data menggunakan analisis univariat dan analisis bivariat. Uji yang digunakan adalah uji Wilcoxon dengan tingkat kemaknaan 0,05.

\section{HASIL PENELITIAN}

Tabel 1 menunjukkan bahwa dapat dilihat bahwa jumlah responden yang berumur 14 tahun 27 orang $(65,9 \%)$ sedangkan responden berumur 13 Tahun adalah 14 orang $(34,1 \%)$ merupakan kelompok umur yang paling rentan.

Tabel 1. Distribusi Frekuensi Responden berdasarkan Karakteristik Umur pada Murid Kelas VIII di SMPN 7 Palu

\begin{tabular}{lcc}
\hline \multicolumn{1}{c}{ Umur (Tahun) } & n & \% \\
\hline 13 & 14 & 34,1 \\
14 & 27 & 65,9 \\
Total & 41 & 100,0 \\
\hline
\end{tabular}

Sumber: Data Primer 2020

Tabel 2 menunjukkan bahwa dari 41 responden yang memiliki persepsi tentang merawat organ reproduksi sebelum dilakukan pendidikan kesehatan pada kategori baik 7 responden $(17,1 \%)$, kategori cukup sebanyak 25 responden $(61,0 \%)$, dan kategori kurang 9 responden $(22,0 \%)$. Sesudah dilakukan pendidikan kesehatan, pada kategori baik 33 responden (80,5\%), dan kategori cukup sebanyak 8 responden $(19,5 \%)$.

Tabel 2. Distribusi Frekuensi Responden berdasarkan Variabel Penelitian pada Murid Kelas VIII di SMPN 7 Palu

\begin{tabular}{lcc}
\hline \multicolumn{1}{c}{ Persepsi } & n & \% \\
\hline Sebelum & & \\
Baik & 7 & 17,1 \\
Cukup & 25 & 61,0 \\
Kurang & 9 & 22,0 \\
Sesudah & & \\
Baik & 33 & 80,5 \\
Cukup & 8 & 19,5 \\
Kurang & 0 & 0,0 \\
Total & 41 & 100,0 \\
\hline Sumber: Data Primer 2020 & &
\end{tabular}


Hasil penelitian pada tabel 3 bivariat dengan menggunakan uji wilcoxon maka didapatkan perbedaan sebelum dan sesudah dilakukan penelitian pendidikan di SMPN 7 Palu sebesar $P$ Value 0,000 $(<0,05)$, sehingga $\mathrm{H} 0$ ditolak atau $\mathrm{Ha}$ diterima, ada pengaruh pendidikan kesehatan terhadap persepsi remaja dalam merawat organ reproduksi.

Tabel 3. Pengaruh Pendidikan Kesehatan terhadap Persepsi Remaja dalam Merawat Organ Reproduksi pada Murid Kelas VIII di SMPN 7 Palu

\begin{tabular}{lccc}
\hline & N & Z & P value \\
\hline $\begin{array}{l}\text { Sebelum dan } \\
\text { Sesudah dilakukan }\end{array}$ & & & \\
$\begin{array}{l}\text { Pendidikan } \\
\text { Kesehatan }\end{array}$ & & -5.471 & 0,000 \\
\hline Sumber: Data Primer 2020 & & \\
\hline
\end{tabular}

Sumber: Data Primer 2020

\section{PEMBAHASAN}

\section{Persepsi remaja sebelum dilakukan pendidikan kesehatan di SMPN 7 Palu}

Persepsi adalah pengalaman tentang objek, peristiwa,atau hubungan-hubungan yang diperoleh dengan menyimpulkan informasi serta melampirkan pesan. Penelitian ini mengukur persepsi merawat organ reproduksi. Hasil pretest penelitian yang didapatkan dari 41 responden yang memiliki persepsi tentang merawat organ reproduksi pada kategori baik 7 responden $(17,1 \%)$, kategori cukup sebanyak 25 responden $(61,0 \%)$, dan kategori kurang 9 responden $(22,0 \%)$.

Menurut asumsi peneliti hal ini disebabkan responden masih duduk dibangku sekolah SMP, dimana respoden tersebut belum mengenal cara menjaga kebersihan organ reproduksi yang benar hal ini dapat dilihat dari kuesioner yang telah diberikan kepada responden, mayoritas persepsi cukup dari responden serta adanya sebagian kecil persepsi kurang cenderung disebabkan oleh pengetahuan remaja (responden) mengenai perawatan organ reproduski.

Persepsi perawatan organ reproduksi yang dimiliki oleh diperbaiaki atau ditingkatkan salah satunya dengan cara mengadakan kegiatan penyuluhan, karena pengertian dari kegiatan penyuluhan merupakan kegiatan pendidikan yang dilakukan dengan menyebar pesan dan menambah keyakinan sehingga masyrakat menjadi tahu sekaligus juga mau dan bisa melakukan anjuran yang ada hubungannya dengan kesehatan

Pengetahuan atau wawasan sangat erat kaitannya dengan informasi yang diperoleh seseorang, artinya apabila seseorang memperoleh informasi yang lebih banyak dan lebih baik dari berbagai media misalnya televisi, radio atau surat kabar, maka hal itu dapat meningkatkan pengetahuan seseorang sekaligus membentuk persepsi seseorang menjadi lebih baik. Dengan demikian dapat disimpulkan bahwa semakin tinggi pengetahuan seseorang maka akan semakin tinggi tingkat kecermatan seseorang terhadap objek persepsi (Notoatmodjo, 2014).

Persepsi dalam arti sempit adalah "penglihatan" yaitu bagaimana cara seseorang melihat sesuatu, sedangkan dalam arti luas, pesepsi adalah "pandangan" yaitu bagaimana seseorang memandang atau mengartikan sesuatu (Desmita, 2017). Dari faktor internal terdapat faktor usia, usia merupakan hal terpenting yang mempengaruhi terhadap persepsi. Semakin cukup umur seseorang akan menjadi lebih matang dalam berfikir dan bekerja (Nugroho, 2016).

\section{Persepsi remaja sesudah dilakukan pendidikan kesehatan di SMPN 7 Palu}

Tingkat persepsi remaja putri setelah diberikan pendidikan kesehatan, mengalami peningkatan nilai persepsi. Dibuktikan dengan nilai diketahui bahwa dari 41 responden yang memiliki persepsi tentang merawat organ reproduksi sesudah dilakukan pendidikan kesehatan pada kategori baik 33 responden (80,5\%), dan kategori cukup sebanyak 8 responden $(19,5 \%)$.

Hasil posttest dalam penelitian ini memperlihatkan bahwa adanya intervensi berupa pendidikan kesehatan dapat memberikan perubahan persepsi mengenai perawatan organ reproduksi. Dari intervensi yang diberikan tersebut, menurut asumsi peneliti para remaja menjadi lebih mengetahui seperti mencebok dengan sembarang asal mereka merasa sudah bersih tetapi setelah diberikan pendidikan mereka sudah mengetahui bagaimana cara mencebok dengan baik dan mereka juga mengetahui tentang tujuan, manfaat serta perawatan organ reproduksi.

Persepsi dapat juga dipengaruhi oleh pengetahuan seseorang. Pendidikan kesehatan merupakan aspek penting dalam meningkatkan 
pengetahuan remaja karena pendidikan kesehatan remaja memiliki persepsi yang baik tentang sesuatu hal sehingga mereka mampu menciptakan dan membangun perilaku yang positif tentang merawat organ reproduksi nantinya (Notoatmodjo, 2014).

Persepsi merawat organ reproduksi yang dimiliki oleh siswi dapat diperbaiki atau ditingkatkan salah satunya dengan cara mengadakan kegiatan penyuluhan, karena pengertian dari kegiatan penyuluhan merupakan kegiatan pendidikan kesehatan yang dilakukan dengan menyebar pesan dan menambah keyakinan sehingga remaja lebih tahu dan mengerti sekaligus juga mau dan bisa melakukan anjuran yang ada hubungannya dengan kesehatan (Machfoedz, 2017).

\section{Pengaruh pendidikan kesehatan reproduksi tentang perawatan organ reproduksi}

Berdasarkan hasil analisis data menggunakan uji Wilcoxon diperoleh nilai bernilai $0,000<0,05$ maka $\mathrm{HO}$ ditolak $\mathrm{Ha}$ diterima. Dapat disimpulkan bahwa ada pengaruh pendidikan kesehatan terhadap persepsi remaja dalam merawat organ reproduksi di SMPN 7 Palu.

Peneliti berpendapat bahwa remaja putri setelah diberikan pendidikan kesehatan mempunyai kualitas persepsi yang meningkat dari sebelum diberikan pendidikan kesehatan tentang kebersihan organ reproduksi. Perubahan-perubahan perilaku dalam diri seseorang dapat diketahui melalui persepsi yaitu sebagai pengalaman yang dihasilkan melalui panca indera. Semakin banyak pendidikan kesehatan tentang merawat organ reproduksi menunjukan bahwa persepsi responden menjadi sangat positif.

Pendidikan kesehatan merupakan suatu penerapan konsep pendidikan di dalam bidang kesehatan untuk membantu individu, kelompok atau masyarakat dalam meningkatkan kemampuan atau perilakunya, untuk mencapai kesehatan secara optimal, memberikan informasi, kesadaran dan sebagainya supaya tidak salah dalam mengartikan sesuatu yang masih belum dimengerti baik dan buruknya. Maka dengan ini, pemberian pendidikan kesehatan pada remaja perlu ditingkatkan agar terhindar dari dampak atau risiko yang dapat ditimbulkan (Syah, 2014).

Pendididkan kesehatan mempunyai peranan yang sangat penting dalam menambah informasi guna meningkatkan pengetahuan dan persepsi yang baik dalam kehidupan masyarakat. Pengalaman yang didapatkan dari informasi melalui pedidikan kesehatan diharapkan dapat memberikan efek persepsi yang positif bagi remaja putri. Semakin banyak remaja putri yang memiliki persepsi positif terhadap perawatan reproduksi semakin baik pula tindakan menjaga kebersihan alat reproduksinya (Yusuf, 2017).

\section{KESIMPULAN DAN SARAN}

Berdasarkan hasil penelitian yang telah dilakukan di SMPN 7 Palu mengenai pengaruh pendidikan kesehatan tentang perawatan organ reproduksi dengan persepsi remaja di SMPN 7 Palu diperoleh hasil penelitian yang menunjukkan bahwa persepsi remaja sebelum dilakuan pendidikan kesehatan tentang merawat organ reproduksi dan persepsi remaja setelah dilakukan pendidikan kesehatan tentang merawat organ reproduksi mengalami peningkatan. Berdasarkan hasil tersebut maka pada penelitian ini dapat disimpulkan bahwa terdapat pengaruh pendidikan kesehatan tentang persepsi remaja dalam merawat organ reproduksi.

Diharapkan kepada pihak sekolah SMPN 7 Palu agar dapat menjalin kerjasama dengan instansi lainnya khusunya pada program kegiatan yang dilakukan oleh Puskesmas tentang kesehatan reproduksi dalam hal pemberian penyuluhan maupun sosialisasi khusunya terkait kesiapsiagaan bencana banjir, sehingga masyarakat sekolah terutama siswa mempunyai persepsi yang baik tentang kesehatan reproduksi. Selain itu, sekolah juga diharapkan agar dapat menyediakan media informasi berupa buku seperti kesehatan reproduksi dan leaflet untuk membantu siswa mendapatkan informasi seputar kesehatan reproduksi.

Diharapkan institusi kesehatan dapat memberikan kegiatan penyuluhan di sekolah SMPN untuk memberikan informasi tentang pentingnya memahami perawatan organ reproduksi. Kepada peneliti selanjutnya agar dapat mengembangkan penelitian ini dengan menambahkan variabel (khusunya perawatan organ reproduksi). Untuk mengetahui variabel lain yang dapat berpengaruh dalam perawatan organ reproduksi.

\section{DAFTAR PUSTAKA}


BKKBN. (2013). Bimbingan Teknis Kesehatan Respoduksi dan Seksualitas yang Komprehensif. BKKBN.

Desmita. (2017). Psikologi Perkembangan Peserta Didik. Remaja Rosdakrya.

Indrawati, K. (2011). Upaya Meningkatkan Pengetahuan tentang Kesehatan Organ Reproduksi Siswi Kelas VIII SMPN 10 Surabaya Melalui Metode Tutor Sebaya Surabaya. E-Journal Dinas Pendidikan Kota Surabaya, 5, 1-11.

Indrawati, T., \& Pitriyani, H. (2016). Hubungan Personal Higiene Organ Genital dengan Kejadian Kanker Seviks di RSUP Dr. Kariadi Kota Semarang. Jurnal Dinamika Kebidanan, 2(1), 1-14. http://jurnal. abdihusada. ac.id/index. php/jurabdi/article/view/14.

Johar, Wiwin., Rejeki, Sri., Khayati, N. (2013). Persepsi dan Upaya Pencegahan Keputihan pada Remaja Putri di SMA Muhammadiyah 1 Semarang. Jurnal Keperawatan Maternitas, 1(1), 37-45. https://jurnal.unimus.ac.id/index.php/JK Mat/article/view/931.

Kementerian Kesehatan Republik Indonesia.
(2013). Buku Saku Pelayanan Kesehatan Ibu di Fasilitas Kesehatan Dasar dan Rujukan (Edisi Pert).

Machfoedz, I. (2017). Statistik Non Parametik. Fitramaya.

Notoatmodjo, S. (2014). Promosi Kesehatan Dan Perilaku Kesehatan. Rineka Cipta.

Nugroho. (2016). Buku Ajar Keperawatan Lanjut Usia. EGC.

Prayitno, S. (2014). Kesehatan Organ Reproduksi Wanita (Cet. 1). Yogyakarta Saufa.

Syah, M. (2014). Psikologi Pendidikan. Rosdakarya.

World Health Organization. (2014). Sexually Transmitte Infection. WHO. http//www.who.int/topics/sexually_trans mitted.

Yusly, E., Indriyani, D., \& Yulis, Z. E. (2015). Pengaruh Pendidikan Kesehatan terhadap Persepsi tentang Kebersihan daerah Genitalia pada Remaja Putri di SMA 1 Pakusari Kabupaten Jember. Universitas Muhammadiyah Jember.

Yusuf, S. (2017). Psikologi Perkembangan Anak. Rosdakarya. 